\title{
Fecundació in vitro del musclo (Mytilus sp.) i seguiment del seu desenvolupament embrionari
}

\author{
Montserrat Bigas, Escola del Mar de Badalona. bbmuntsa@wanadoo.es \\ Laia Pibernat, estudiant de Biologia \\ Montserrat Cabello, Centre de Documentació i Experimentació en Ciències i Tecnologia (CDECT) \\ mcabello@pie.xtec.es
}

L'objectiu d'aquesta experiència és induir l'alliberament dels gàmetes dels musclos $i$, tot seguit, forçar-ne la fecundació. Això ens permetrà seguir, pas a pas, el desenvolupament embrionari des de la fase de zigot fins a l'estadi de larva.

Comprem al mercat musclos de roca, o bé de Galícia, assegurant-nos que són frescos. És convenient embolicar-los ràpidament, si pot ser al mateix mercat, amb un drap o tovallola vella xop amb aigua de mar. Si l'experiència no es fa el mateix dia cal deixar els musclos a la nevera embolicats amb el mateix drap (fig.1).

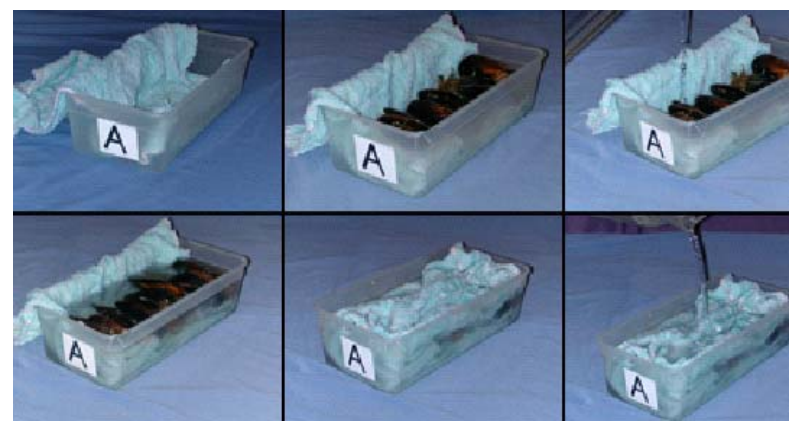

Fig.1. Sistema d'emmagatzematge dels musclos abans de començar l'experiment.

L'alliberament dels gàmetes, primera part de l'experiment, el durem a terme mitjançant el mètode del xoc tèrmic, modificat a partir del mètode desenvolupat per Kyozuca et al, (1994). Primer posem els musclos, un mínim de deu, en una safata amb aigua de mar que haurem mantingut a la nevera i els posem al congelador durant 30 minuts. Mentre tant, escalfem 3 litres d'aigua de mar al bany Maria fins que assoleixi una temperatura de $28-30{ }^{\circ} \mathrm{C}$, (l'aigua de mar s'ha de posar al bany Maria dins de recipients tancats per evitar que s'evapori i en variï la salinitat). Un cop passats els 30 minuts, retirem els musclos del conge- lador i els posem, un a un, en un vas de precipitats o bé en un cul d'ampolla de plàstic, les ampolles d'aigua de litre i mig funcionen molt bé. Cobrim cada musclo amb uns $150 \mathrm{ml}$ de l'aigua de mar que hem escalfat $\left(28-30{ }^{\circ} \mathrm{C}\right)$. En aquest segon període, que durarà 55 minuts, pot haver-hi algun musclo que comenci a alliberar gàmetes però aquests no els farem servir.

A la fi d'aquest segon període, decantarem l'aigua calenta i la substituïm amb aigua de mar a 10-12 ${ }^{\circ} \mathrm{C}$. A partir d'aquest moment i durant un interval d'aproximadament dues hores, hem d'observar els flascons ja que si tot va bé, hem de veure l'alliberament dels gàmetes.

Les femelles alliberen uns cordons de color ataronjat que ràpidament precipiten al fons dels flascó. En canvi, els mascles alliberen un fluid blanquinós que es dissol ràpidament amb l'aigua de mar fent que aquesta s'enterboleixi. Un cop haguem confirmat que hi ha alliberament, esperarem uns minuts fins que el procés s'aturi i retirarem els musclos de dins els flascons. Abans de procedir a la fecundació i per assegurar-nos que realment tenim gàmetes, prenem una mostra tant del flascó on creiem que hi ha oòcits com del que hi ha espermatozoides $i$ l'observem al microscopi òptic (fig.2).

La fecundació la farem en un vas de precipitats on hi posarem $200 \mathrm{ml}$ d'aigua de mar a temperatura ambient, hi afegirem $2 \mathrm{ml}$ de la mostra d'oòcits, és important agafar-los del fons del flascó on estan precipitats. Després homogeneïtzem la suspensió d'espermatozoides en aigua de mar remenant-la amb una pipeta; n'agafem $48 \mathrm{ml}$ que afegirem al vas de precipitats on prèviament hi hem afegit els oòcits. Just en el moment d'afegir-hi els espermatozoides anotarem l'hora i la considerarem el temps 0. 


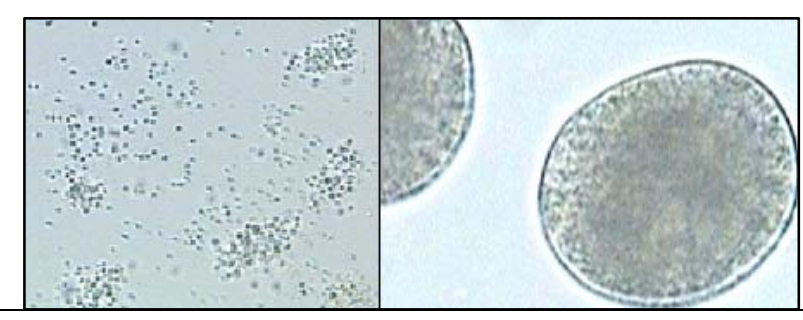

Fig.2. Mostres de gàmetes observades al microscopi òptic.

Esquerra: espermatozoides, 400X

Dreta: oòcits, $400 \mathrm{X}$

A partir d'aquest moment, anirem prenent mostres de forma periòdica, anotant el temps, i les observarem al microscopi òptic per tal de veure les diferents fases del desenvolupament embrionari: clivellament, mòrula, gàstrula, blàstula, larves (fig.3). La presa de mostres s'ha de fer durant 48 hores.

En el moment d'agafar les mostres, és important remenar la suspensió de gàmetes en aigua de mar amb una vareta de vidre per homogeneïtzar-la. Amb una pipeta agafem una mostra en el centre del vòrtex que es forma al remenar, just quant aquest està a punt de desaparèixer; d'aquesta manera ens assegurem que agafem gàmetes 0 embrions en les diferents fases. La millor època per fer aquesta experiència és durant els mesos de gener i febrer.

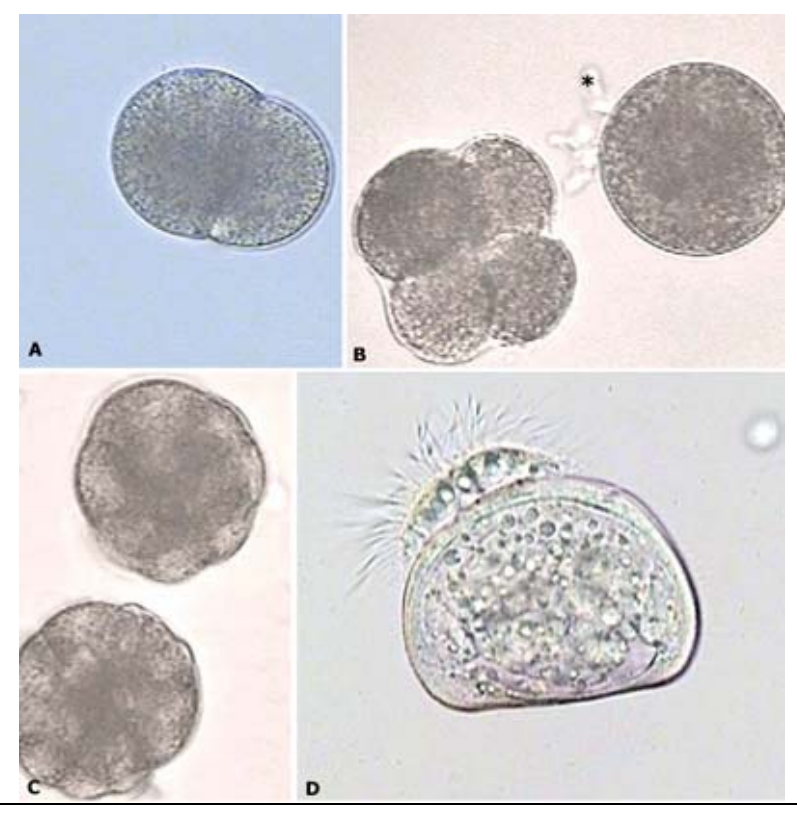

Fig.3. Diferents fases del desenvolupament embrionari:

A. Primera divisió

B. Segona divisió, 4 cèl.lules i oòcit fecundat en l'escorça del qual es pot observar el cos polar (assenyalat $a m b$ * a la figura)

C. Mòrules

D. Larva observada a les $48 \mathrm{~h}$ d'haver fet la fecundació. Totes les imatges a $400 \mathrm{x}$

\section{Bibliografia}

Kyozuca, Kelichiro i Osani, Kenzi (1994). "Funtions of egg envelope of Mytilus edulis during fertilization." Bulletin of the marine biological station of Aamushi Tôhoku University. Vol.19. n2. 